\title{
Towards Chip-Based Salinity Measurements for Small Submersibles and Biologgers
}

\author{
Jonas Jonsson, ${ }^{1}$ Katarina Smedfors, ${ }^{1}$ Leif Nyholm, ${ }^{2}$ and Greger Thornell ${ }^{1}$ \\ ${ }^{1}$ Angström Space Technology Centre, Department of Engineering Sciences, Uppsala University, Uppsala, Sweden \\ ${ }^{2}$ Department of Chemistry, The Ångström Laboratory, Uppsala University, Uppsala, Sweden
}

Correspondence should be addressed to Greger Thornell; greger.thornell@angstrom.uu.se

Received 25 February 2013; Revised 16 September 2013; Accepted 25 September 2013

Academic Editor: Emilio Fernández

Copyright (c) 2013 Jonas Jonsson et al. This is an open access article distributed under the Creative Commons Attribution License, which permits unrestricted use, distribution, and reproduction in any medium, provided the original work is properly cited.

\begin{abstract}
Water's salinity plays an important role in the environment. It can be determined by measuring conductivity, temperature, and depth (CTD). The corresponding sensor systems are commonly large and cumbersome. Here, a $7.5 \times 3.5 \mathrm{~mm}$ chip, containing microstructured CTD sensor elements, has been developed. On this, $1.5 \mathrm{~mm}^{2}$ gold finger electrodes are used to measure the impedance, and thereby the conductivity of water, in the $\mathrm{MHz}$ frequency range. Operation at these frequencies resulted in higher sensitivities than those at sub-MHz frequencies. Up to $14 \mathrm{k} \Omega$ per parts per thousand salt concentration was obtained repeatedly for freshwater concentrations. This was three orders of magnitude higher than that obtained for concentrations in and above the brackish range. A platinum electrode is used to determine a set ambient temperature with an accuracy of $0.005^{\circ} \mathrm{C}$. Membranes with Nichrome strain gauges responded to a pressure change of 1 bar with a change in resistance of up to $0.21 \Omega$. A linear fit to data over 7 bars gave a sensitivity of $0.1185 \Omega /$ bar with an $R^{2}$ of 0.9964 . This indicates that the described device can be used in size-limited applications, like miniaturized submersibles, or as a bio-logger on marine animals.
\end{abstract}

\section{Introduction}

In the field of oceanography, salinity is an important property of water. Simply put, it is defined as the total amount of dissolved salts in one kilogram of water. The degree of salinity can be expressed in parts per thousands, where the oceans have an average salinity close to $35 \%$, and freshwater has salinity below $0.5 \%$. Salinity is constantly changing through events like evaporation, precipitation, and ice formation and melting. It is an essential ecological and environmental factor that has a great influence on which kind of life can prevail and which plants can grow. It affects water usage all over the world, determining which waters are potable and which can be used for irrigation. It is therefore important to be able to measure and monitor the salt content of water. Furthermore, the salinity of water plays a critical role in the climate of the planet, where the density, which is usually not measured directly but calculated from salinity, temperature, and pressure measurements, is the driving force behind the world's ocean circulation through convection, the rising and sinking of water [1]. The salinity and temperature of water also affect other phenomena, such as the solubility of oxygen $\left(\mathrm{O}_{2}\right)$ and carbon dioxide $\left(\mathrm{CO}_{2}\right)$, the vaporization and ionization of water, and the dissolution of solid calcium carbonate $\left(\mathrm{CaCO}_{3}\right)$ [2]. As $\mathrm{CO}_{2}$ from the atmosphere dissolves in the oceans [3], the $\mathrm{pH}$ is lowered, and the oceans are acidified [4], affecting the coral reefs $[5,6]$, calcareous planktons [7], and other organisms containing calcium carbonate, including the deep-ocean biota [8].

Being an important property of water, it is, however, difficult to measure the amount of dissolved salts in reality. As of 1978, salinity is measured using the Practical Salinity Scale (PSS), expressed as a dimensionless ratio between the conductivity of water and that of a standard potassium chloride ( $\mathrm{KCl})$ solution [9], and calibrated for by temperature and depth. By knowing conductivity, temperature, and depth, additional properties of water can be calculated, such as the specific volume anomaly, density anomaly, freezing point temperature, specific heat, adiabatic lapse rate, potential temperature, and sound speed [10]. 
Salinity can also be indirectly measured from the refractive index [11], speed of sound [12], and water density [12]. Furthermore, the Aquarius/SAC-D satellite, launched in 2011, will make radiometric observations from which the salinities of Earth's ocean surface waters can be derived [13]. However, since the average depth of the oceans is $3800 \mathrm{~m}$, these measurements will have to be correlated with measurements at depths in order to obtain more complete understanding of the planet's oceans and their effect on the world we live in. Worth mentioning in this context is also the European Space Agency's counterpart: Soil Moisture and Ocean Salinity (SMOS) [14], which uses a different but complementary interferometric technique used on a satellite of theirs launched in 2009.

To measure the three parameters of water: conductivity, temperature, and depth (CTD), sensors have commonly been used since the 1960s, when they became essential tools in the field of oceanography [15]. CTD instruments can be found on most research vessels today. Often combined with a Niskin bottle rosette for simultaneous sampling of water, they are large and cumbersome devices, hoisted down into the water from ships using cranes, or hanging under buoys. This, however, necessitates the use of a ship large enough to deploy and recover these instruments, restricting the range and accessibility of them. Furthermore, due to the limited number of research vessels, these measurements are restricted over space and time.

As for the performance, scientists can require instruments with resolution of the order of parts per millions, with the best current systems measuring salinity with an uncertainty of \pm 0.005 for conductivity and with temperatures measured to $\pm 0.001^{\circ} \mathrm{C}$ and pressures to $\pm 0.65 \mathrm{dbar}$ [15].

To enable better spatial and temporal resolutions of measurements, the Earth observations system, ARGO, was developed. These automated floats, now numbering about 3000 , are about two meters long and weigh about $25 \mathrm{~kg}$. They have been reported to have salinity uncertainty of 0.01 , where the temperature measurements are precise to $0.005^{\circ} \mathrm{C}$ and pressures to 5 dbars [16].

Alternatively, miniaturized CTD sensors, using techniques such as microelectromechanical systems (MEMS) technology, although perhaps at the expense of accuracy, have the potential to be mounted on even smaller platforms [17] and combined with devices, such as a miniaturized sampler [18]. Thus, areas not possible to reach with the larger systems can be accessed. Potentially, these sensors could also be used as biologgers on marine animals [19, 20], acting as measurement platforms, or as a stand-alone instrument in previously unfeasible applications. In addition, redundancy can be achieved using miniaturized sensors, since several CTD setups can be accommodated in an instrument with marginal mass and volume penalty.

A $4 \times 4 \mathrm{~mm}$ salinity sensor element with an uncertainty of 0.5 PSU has been presented [21]. Determination of conductivity was reported with an uncertainty of $\pm 0.06 \mathrm{mS}$. The temperature sensor was reported to have a resolution of $0.01^{\circ} \mathrm{C}$. However, its uncertainty was stated to be both $\pm 0.065^{\circ} \mathrm{C}$ and $\pm 0.13^{\circ} \mathrm{C}$, and it is unclear which of these values is correct. The pressure sensor was stated to have an uncertainty of 0.1 bar. However, details on the evaluation of the temperature and pressure sensor parts were sparse.

An even more recent publication by the same authors [22] reports an uncertainty of \pm 0.1 PSU for a different version of the sensor chip, being $3.0 \times 7.4 \times 0.8 \mathrm{~mm}^{3}$ in size, probably due to a larger electrode area. The sensitivity of the pressure sensor was now reported to be $1.44 \times 10^{-3} \mathrm{dbar}^{-1}$. The temperature sensor was reported to have a temperature coefficient of resistance (TCR) of $0.0029 \mathrm{~K}^{-1}$.

A miniature, low-cost CTD system for coastal salinity measurements, using printed circuit board (PCB), has also been reported [23]. Uncertainties for conductivity of $\pm 1.47 \%$, temperature of $\pm 0.546^{\circ} \mathrm{C}$, and pressure of \pm 0.02 bar were estimated. However, the design included a commercial sensor, and the overall design of the CTD was approximately $10 \mathrm{~cm}$ in diameter and $10 \mathrm{~cm}$ in length.

A more current development of this system [24], still based on PCB, to be used in biologger applications, decreased the size to a $90 \times 28 \mathrm{~mm}$. However, in addition to a commercial pressure sensor, with an uncertainty of $1 \%$, it employed a commercial thermistor with an uncertainty of $\pm 0.01^{\circ} \mathrm{C}$.

An even more recent device is the conductivity and temperature sensor by Huang et al. [25], which uses a sevenelectrode conductivity cell offering a precision of $0.03 \mathrm{mS} / \mathrm{cm}$ in the $25-55 \mathrm{mS} / \mathrm{cm}$ range. The platinum sensor elements are routed on a $35 \times 20 \mathrm{~mm}$ glass chip.

Clearly, there exists a range of applications with varying requirements, as well as a number of approaches to embodiments of, in particular, miniaturized CTD instruments. From these accounts, it is tempting to find a correlation between the need for very high quality, and, perhaps, fewer or more localized measurements, on one hand, and great distribution of measurements (in space or time) at low cost, and lower demands on the data quality, on the other. So far, miniaturized instruments appear to target the latter need, not seldom proposing the use of integrable devices. This work, which describes the preliminary design, manufacturing, and laboratory evaluation of a miniaturized measurement device, containing sensor elements for conductivity, temperature, and depth, with the potential to be used in applications requiring small CTD instruments, is not an exception in this respect. An example of a platform targeted for this instrument is the miniature submersible DADU [26], where size is of great essence, and for which the suggested missions of relevance are of an exploratory nature, striving to gather early but multifaceted data to pave the way for more scientific missions.

\section{Background}

2.1. Salinity of Water. The salinity classification of water ranges from less than $0.5 \%$ for fresh water to over $50 \%$ o for brine, Table 1. The Earth's oceans have salinity of 34.60 to $34.80 \%$ [15], the Baltic Sea salinity of around 9\%o, and the Mediterranean Sea salinity of about $38 \%$, whereas water in the subglacial Lake Vostok in Antarctica has been calculated to a value of $0.03 \%$ [27]. 
TABLE 1: Salinity classification of water $[28,29]$ and some example environments.

\begin{tabular}{lcc}
\hline Environments & Examples & Salinity $(\%)$ \\
\hline Freshwater & & $<0.5$ \\
& Lake Vostok [27] & 0.03 \\
Brackish water & Drinking water & $<0.5$ \\
& & $0.5-30$ \\
Normal seawater & Agriculture [30] & $<2$ \\
& Baltic Sea & 9 \\
Brine water & Average seawater [15] & $30-40$ \\
& Mediterranean & 34.7 \\
& & $>50$ \\
\hline
\end{tabular}

Although similar, the composition of the oceans differs slightly from place to place across the globe, and in enclosed water bodies and in estuaries, the difference can be substantial $[32,33]$.

2.2. Salinity Calculation. The total amount of dissolved salts, containing, for example, chloride, sodium, magnesium, sulfate, calcium, and potassium ions, in grams in one kilogram of water is defined as absolute salinity, $S_{A}$. However, in practice, this quantity cannot be measured directly. Instead, a practical salinity, $S$, is used, according to the Practical Salinity Scale of 1978 (PSS) [34]. Practical salinity is defined as the ratio of the measured electrical conductivity of the water sample to that of a standardized potassium chloride $(\mathrm{KCl})$ solution and has an uncertainty of \pm 0.003 [15]. Hence, it is a unitless number and not an SI quantity. Through PSS, S can be calculated [35] according to

$$
S=a_{0}+a_{1} K_{15}^{1 / 2}+a_{2} K_{15}+a_{3} K_{15}^{3 / 2}+a_{4} K_{15}^{2}+a_{5} K_{15}^{5 / 2},
$$

where

$$
\begin{gathered}
a_{0}=0.00080, \\
a_{1}=-0.1692, \\
a_{2}=25.3851, \\
a_{3}=14.0941, \\
a_{4}=-7.0261, \\
a_{5}=2.7081, \\
K_{15}=\frac{C(S, 15,0)}{C(\mathrm{KCl}, 15,0)},
\end{gathered}
$$

where $C(S, 15,0)$ is the conductivity of the water sample, having salinity of $S$, at a temperature of $14.996^{\circ} \mathrm{C}$ (ITS-90 [36]) and a standard atmospheric pressure, 101,325 $\mathrm{Pa}$ [15], and $C(\mathrm{KCl}, 15,0)$ is the conductivity of the standard solution, containing $32.4356 \mathrm{~g}$ of $\mathrm{KCl}$ in a $1.000000 \mathrm{~kg}$ solution, at $15^{\circ} \mathrm{C}$ and standard atmospheric pressure [15].
According to the above definition of PSS, all water that has the same conductivity also has the same $S$, independent of what fraction of different ions are dissolved in the water.

For in situ measurements, at different pressures and temperatures, additional equations are needed [15, 35]. PSS is, however, only applicable for temperatures of -2 to $35^{\circ} \mathrm{C}$, and the practical salinity only at 2 to 42 [36].

Practical salinity units (PSU) are sometimes mentioned as a unit for $S$ and a substitute for parts per thousand. However, PSS is unitless and PSU is not part of its definition [15].

Absolute salinity differs from practical salinity by about $0.5 \%$ [15]. A new measure of salinity named Reference Salinity, $S_{R}$, has been proposed to more accurately represent $S_{\mathrm{A}}$ in artificial seawater solutions [37]. It is also intended to be an SI-based extension of $S_{A}$.

Due to the definition of PSS, it cannot be said that, for example, an $S$ of 35 exactly equals that of $35 \mathrm{~g}$ of substance dissolved in one liter of water. For simplicity, however, parts per thousand $(\%)$ is used in this work to define the concentration of $\mathrm{NaCl}$ salt in saline solutions.

2.3. Conductivity Calculation. Two electrodes immersed in water can be used to measure its electrical conductivity. When an electrical potential is applied over the electrodes, an ion current, proportional to the ion concentration, will flow between them. An alternating voltage is generally used to avoid polarization of the electrode surfaces. The conductance, $G$, which is the reciprocal of the resistance, $R$, can be obtained from this measurement in accordance with Ohm's law. In the case of two parallel plates facing each other, and where fringe effects are neglected, the conductivity, $\sigma$, can be calculated as

$$
\sigma=G \theta
$$

where the cell constant, $\theta$, is the ratio of the distance between the electrodes and their cross-section area. The unit of conductivity is Siemens per meter, S/m, where the unit for conductance, $S$, is not to be confused with the notation of salinity.

For thin-film electrodes positioned side by side on a flat surface in a finger comb like manner, the expression for the cell constant becomes more complicated [38]:

$$
\theta=\frac{1}{(N-1) L} \times \frac{2 \phi(\Gamma)}{\phi\left(\left(1-\Gamma^{2}\right)^{1 / 2}\right)},
$$

where

$$
\begin{gathered}
\phi(\Gamma)=\int_{\zeta=0}^{1} \frac{d \zeta}{\left[\left(1-\zeta^{2}\right)\left(1-\Gamma^{2} \zeta^{2}\right)\right]^{1 / 2}}, \\
\Gamma=\frac{D}{D+W}
\end{gathered}
$$

and $L$ and $W$ are the length and width of the electrodes, respectively, $D$ is the distance between them, $N$ is the number of fingers, and $\zeta$ is integrated over from 0 to 1 . By knowing the cell constant, the conductivity can be calculated using (4). 
2.4. Temperature. The resistance, $R$, of a conductor can be calculated through

$$
R=\frac{\rho L}{A}
$$

where $\rho$ is the resistivity of the material, $L$ is the conductor's length, and $A$ its cross-sectional area, that is, the product of the width, $W$, and height, $H$. The resistance of the conductor depends on the temperature, according to

$$
R=R_{\text {cal }}\left(1+\alpha\left(T-T_{\text {cal }}\right)\right),
$$

where $R$ is the resistance at temperature $T, R_{\text {cal }}$ is the resistance at temperature $T_{\text {cal }}$, and $\alpha$ is the TCR at $T_{\text {cal }}$ [39].

Due to more accurate measurements of absolute temperature, the International Practical Temperature Scale of 1968 (ITPS-68), which was used for PSS, was revised to the current International Temperature Scale of 1990 (ITS-1990). These two temperature scales differ slightly from each other.

Even though the resolution of oceanographic thermometers can be down to the millidegree, there are uncertainties in the order of a few millidegrees in the temperature scale itself [15].

2.5. Pressure. In oceanography, pressure is routinely measured in decibars (dbar), since dbar is almost equivalent to the depth of water in meters; that is, at a depth of $1 \mathrm{~m}$, the pressure is $1 \mathrm{dbar}$ above the atmospheric pressure and at depth of $1000 \mathrm{~m}$, the pressure is $1000 \mathrm{dbar}$ above the atmospheric pressure. To convert to SI units, $1 \mathrm{dbar}$ is equal to approximately $10^{4}$ Pascal $(\mathrm{Pa})$.

A pressure sensor designed with a sealed cavity, where one side has a thin membrane and the others more rigid walls, can be used as a depth sensor, as increasing external pressure will increase the deflection of the membrane. By using a meander structure of a strain sensitive material attached on the membrane, this deflection, and thus the external pressure, can be related to a resistance change in the meander.

The relationship between the strain, $\varepsilon$, and the resistance in the meander lead structure can be expressed as

$$
\varepsilon=\frac{\Delta R}{R_{\mathrm{cal}} \times \mathrm{GF}},
$$

where $\Delta R$ is the resistance change from the strain, $R_{\mathrm{cal}}$ is the reference resistance when being under no strain, and GF is the gauge factor for the material [39].

\section{Design}

For a prior and preliminary evaluation of designs, 6 different conductivity sensor elements, 3 different temperature sensor elements, and a set of 4 pressure sensor elements, designated for different pressure regions, were designed, manufactured, and evaluated. Furthermore, electrodes to enable measurements of $\mathrm{pH}$ and $\mathrm{Cl}^{-}$concentrations were included in the design. Chlorinity adds to the information on composition of the salts in the water and is, as of PSS-78, regarded a property separate from salinity of seawater [34]. However, these two

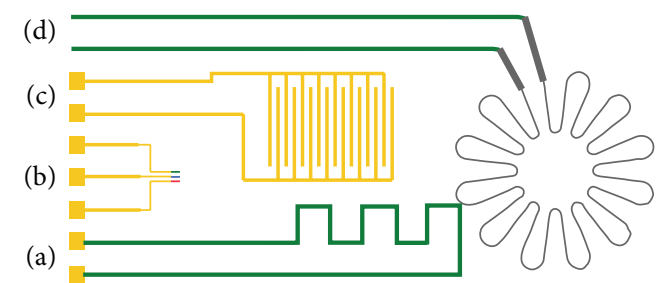

FIGURE 1: Schematic top view of a design containing (a) a temperature sensor, (b) three relatively small electrodes for $\mathrm{pH}$ and $\mathrm{Cl}^{-}$ concentration, (c) conductivity electrodes, and (d) a strain gauge for the pressure membrane sensor. The design is $7.5 \times 3.5 \mathrm{~mm}$ in size.

sensors have not been developed further at this stage and will not be investigated in this work. Also, all but one of the conductivity sensor elements and one of the temperature sensor elements were omitted, since they were used for design verification only.

An example of an electrode layout of a $7.5 \times 3.5 \mathrm{~mm}$ chip to contain the different sensor elements is given in Figure 1.

The whole CTD system, including the sensor chip, electronics, and batteries, is estimated to fit inside a volume of an ordinary matchbox.

The environmental conditions, which the CTD eventually is aimed to operate under, are salinities covering fresh to brine water in a temperature range of -5 to $40^{\circ} \mathrm{C}$ at depths between 0 and $1000 \mathrm{~m}$.

In the following subsections, each sensor element will be further described.

3.1. Conductivity. The conductivity sensor selected for further investigation contains two 8-fingered gold ( $\mathrm{Au}$ ) electrodes. Each electrode finger has a length of $1000 \mu \mathrm{m}$ and a width of $50 \mu \mathrm{m}$. The electrode gap is $50 \mu \mathrm{m}$. A gold lead from each electrode extends to bond pads on the left side of the chip, Figure 1.

3.2. Temperature. The temperature sensor was designed as a resistive thermal device (RTD). Platinum (Pt) was selected as the sensor material since it has a good linear resistanceto-temperature relationship and has a low reactivity with surrounding medium. It is also the material of choice in ITS90 [36]. The temperature-sensing element was designed with a length of $11.9 \mathrm{~mm}$ and a width of $150 \mu \mathrm{m}$.

3.3. Depth. To design the pressure sensors, analytical calculations and simulation software were used. Equations for the pressure-induced deflection of a flat diaphragm with a rigid center were used [40]. The results from these calculations were correlated with the results from finite element analysis (FEA), using COMSOL Multiphysics (ver. 4.1, COMSOL $\mathrm{AB}$, Stockholm, Sweden), where the von Mises stresses were investigated and compared with the yield strength of silicon [41].

The membrane thickness is denoted by $t$, the outer membrane radius $r$, the gap between the bottom and the rigid center $g$, and the radius of the rigid center rc, Figure 2 . The channels encircling the membrane cavity, (3) in Figure 2, 


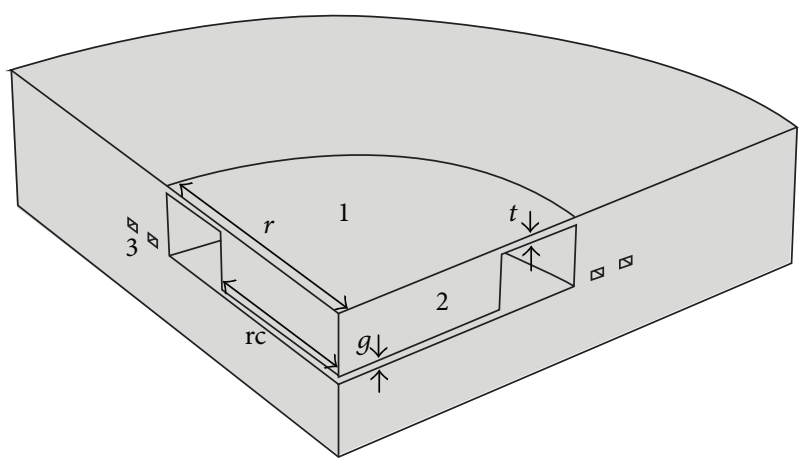

FIGURE 2: Cross-section (one quarter) of a pressure sensor design showing (1) the membrane surface, (2) the rigid center, and (3) the channels used to handle excess glue during fabrication.

TABLE 2: Design parameter of pressure sensors (cf. Figure 2).

\begin{tabular}{lccccc}
\hline Design & $t(\mu \mathrm{m})$ & $r(\mu \mathrm{m})$ & $g(\mu \mathrm{m})$ & $\mathrm{rc}(\mu \mathrm{m})$ & $\begin{array}{c}\text { Maximum pressure } \\
(\mathrm{dbar})\end{array}$ \\
\hline P1 & 70 & 1000 & 40 & 475 & 390 \\
P2 & 70 & 1000 & 40 & 575 & 650 \\
P3 & 70 & 1000 & 40 & 625 & 910 \\
P4 & 70 & 1000 & 40 & 675 & 1330 \\
\hline
\end{tabular}

are included to prevent glue from entering the cavity when the structured chip is capillary glued to the rigid bottom. The channels are etched to the same depth as the gap $g$ and are $50 \mu \mathrm{m}$ wide. The inner channel is placed $75 \mu \mathrm{m}$ from the cavity edge, and the spacing between the two channels is also $75 \mu \mathrm{m}$.

Four pressure sensor elements, denoted by $\mathrm{P} 1$ through $\mathrm{P} 4$, each able to withstand a portion of the specified operating range of a depth of 0 to $1000 \mathrm{~m}$, and so intended to work together as a set, were designed, Table 2.

The protruding rigid center is intended to halt further vertical movement of the membrane against the bottom wafer when the specified maximum pressure has been reached, in order to prevent ruptures. Thus, each individual sensor membrane is designed to deflect with pressure in its respective range, whereas all sensor elements are designed to withstand the pressure at a depth of $1000 \mathrm{~m}$.

The rigid center also provides the membrane with some stability and concentrates the deflections where a meandershaped strain gauge on top measures the deflection of the membrane as a function of the external pressure. The material choice of the meander structures was Nichrome (NiCr), an alloy of nickel $(\mathrm{Ni})$, and chromium $(\mathrm{Cr})$ which has a high sensitivity to strain forces. However, since this material is quickly covered by chromium oxide making it difficult to connect electrically to the leads by wire bonding, Au thinfilm connectors, overlapping with the deposited $\mathrm{NiCr}$ leads, are employed. Two additional $\mathrm{NiCr}$ meander structures were added to rigid parts of the chip to act as temperaturecompensating resistors.
Since the vertical dimensions for all depth sensor designs were the same, they could be manufactured simultaneously, using the same etching steps.

\section{Manufacturing}

Conventional MEMS processes and techniques were used to manufacture the different sensor components. A $280 \mu \mathrm{m}$ thick double-sided polished 4-inch (100) silicon $(\mathrm{Si})$ wafer (Topsil Semiconductor Materials A/S, Frederikssund, Denmark) was used as the substrate material. A standard RCA cleaning step was performed before an $1800 \mathrm{~nm}$ thick layer of silicon oxide, $\mathrm{SiO}_{2}$, was thermally grown in a vertical furnace ( $\mu$ TF-6, Koyo Lindbergh Co. Ltd., Tenri, Japan) at $1050^{\circ} \mathrm{C}$ in 17 hours. The thickness was verified using an interferometer (ELMES-SP, Leica Microsystems GmbH, Wetzlar, Germany).

The wafer was cleaned using the RCA process before treatment in a vapor primer oven (Star 2000, Imtec Accubath, Sunnyvale, CA). A $1 \mu \mathrm{m}$ thick layer of a positive photoresist (Microposit S1813, Rohm and Haas Company, Philadelphia, PA, USA) was spin deposited on the topside (BLE Delta 20) and soft baked at $115^{\circ} \mathrm{C}$ for $60 \mathrm{~s}$ on a hot plate (BM Delta 150). In the same way, a $1 \mu \mathrm{m}$ thick layer was applied to the bottom side, and the wafer was baked at $90^{\circ} \mathrm{C}$ for $20 \mathrm{~min}$ in a furnace (Memmert GmbH, Schwabach, Germany). The topside of the wafer was exposed for $6 \mathrm{~s}$ (Karl Süss, SUSS MicroTec AG, Garching, Germany) through a Cr-glass mask containing the design of marks to align subsequent masks with the wafer. The wafer was developed for $5 \mathrm{~s}$ (Microposit 351, Rohm and Haas Company, Philadelphia, PA), to develop part of the design transferred to the topside's photoresist. Backside alignment was used to align a mask containing part of the membrane design, with the patterns partly developed on the topside of the wafer. The photoresist was exposed and the wafer was developed for an additional $45 \mathrm{~s}$. The wafer was hard baked in a horizontal position at $120^{\circ} \mathrm{C}$ for $20 \mathrm{~min}$ in the furnace. A descum process was performed in $\mathrm{O}_{2} / \mathrm{N}_{2}$ plasma at $50 \mathrm{~W}$ for 60 s (Tepla 300, Technics Plasma GmbH, Munich, Germany) to remove photoresist residues.

The patterned layer was used as a mask to etch the exposed part of the $\mathrm{SiO}_{2}$ layer in buffered hydrofluoric acid for $30 \mathrm{~min}$. This structured $\mathrm{SiO}_{2}$ layer was later to be used in the second $\mathrm{Si}$ etching step. The wafer was stripped from photoresist in acetone and IPA, after which a descum process was performed.

A $150 \mathrm{~nm}$ thick layer of aluminum (Al), to be used as a first Si etching mask, was deposited on the bottom side of the wafer using a magnetron sputter (CS 730S, von Ardenne Anlagentechnik GmbH, Dresden, Germany). A lithography step, as described above, was performed to transfer the second part of the membrane pattern into a S1813 layer. The exposed $\mathrm{Al}$ was wet etched for $2 \mathrm{~min}$ at $40^{\circ} \mathrm{C}$ in $\mathrm{H}_{3} \mathrm{PO}_{4}: \mathrm{CH}_{3} \mathrm{COOH}: \mathrm{HNO}_{3}(29: 5: 1)$ after which the wafer was stripped of resist.

The patterned Al layer was used as the mask in the subsequent deep reactive ion etching (DRIE) of $\mathrm{Si}$ (110 S/DE, Tegal Corporation, Petaluma, CA). The main cavity was etched $170 \mu \mathrm{m}$, as verified using a stylus profilometer (Veeco 
Dektak 150, Bruker Corporation, Billerica, MA). The wafer was stripped of $\mathrm{Al}$, exposing the membrane cavity structures in the $\mathrm{SiO}_{2}$ layer, which were used as the mask for a second DRIE step of additional $40 \mu \mathrm{m}$, extending the depth of the main cavity to $210 \mu \mathrm{m}$ and forming the glue-stop channels and the gap for the rigid center, Figure 2.

To pattern the topside, the wafer was cleaned in RCA and coated with $15 \mathrm{~nm}$ of e-beam-evaporated $\mathrm{Cr}$ followed by $200 \mathrm{~nm}$ resistively evaporated Au (Edwards Auto 306 FL400, BOC Ltd., Crawley, England). Another lithography step was performed to create a photoresist etch mask for the Au electrodes etched for about 4 min in $\mathrm{I}_{2}: \mathrm{KI}: \mathrm{H}_{2} \mathrm{O}(1: 4: 40)$ at RT. The wafer was stripped of resist in acetone and IPA, and the Cr was etched (Chromium etch, Sunchem AB, Partille, Sweden) for $5 \mathrm{~s}$ at RT, using the previously etched Au layer as mask.

For the NiCr and Pt electrode layers, lift-off processes instead of etching were used. Primer was applied to the top surface before a $4 \mu \mathrm{m}$ thick negative photoresist (ma-N 1440, Micro Resist Technology GmbH, Berlin, Germany) was applied, using the spin coater at $250 \mathrm{rpm}$ for $15 \mathrm{~s}$ followed by $3000 \mathrm{rpm}$ for $30 \mathrm{~s}$. The resist was soft baked on the hot plate at $150^{\circ} \mathrm{C}$ for $4 \mathrm{~min}$ after which it was exposed for $2 \times 21 \mathrm{~s}$ and subsequently developed for $4 \mathrm{~min}$ (ma-D 533S, Micro Resist Technology GmbH, Berlin, Germany). Finally, the resist was hard baked in the oven for $45 \mathrm{~min}$, starting at $70^{\circ} \mathrm{C}$, and set to ramp up to $100^{\circ} \mathrm{C}$. The wafer was descummed before the electrode layer was deposited. A $300 \mathrm{~nm}$ thick film of $\mathrm{NiCr}$, using a NiCr target sheet (Ni:Cr:C:Fe:Si:Ti 72-76:18$21: 0.08-0.13:<5:<1: 0.2-0.6$ wt-\%, Goodfellow Cambridge Limited, Huntingdon, England), was deposited in a tabletop sputter (Emitech). For the Pt electrode, a $15 \mathrm{~nm}$ thick titanium (Ti) adhesion layer was deposited before a $150 \mathrm{~nm}$ thick Pt film was deposited in an evaporator (PVD 75, Kurt J. Lesker Company, Clairton, PA). Lift-off was performed in an acetone-filled ultrasonic bath, whereupon the wafer was rinsed in IPA and dried. The thicknesses of the electrodes were verified using the stylus profilometer.

Finally, the wafer was coated with a protective layer of S1813 photoresist for the subsequent dicing (Disco DAD 361, DISCO Corporation, Tokyo, Japan). (In a future application, the chips will be coated with a protective layer, such as SU-8, except for the conductivity electrodes, which should be in direct contact with the liquid.)

Before test devices were manufactured, the chip with the thin-film electrodes was annealed in an oven at $300^{\circ} \mathrm{C}$ for about 5 days. After this, a glass sheet, diced to the same dimensions as the Si chip, was clamped against its bottom side, and a two-part epoxy (EPO-TEK 301, Epoxy Technology, Inc., MA) was mixed and allowed to be drawn in by capillary action, after which it was cured in an oven at $65^{\circ} \mathrm{C}$ for $1 \mathrm{~h}$, creating sealed-off cavities underneath the pressure membranes.

The chip was glued (Crystalbond 509, Aremco Products, Inc., USA) to an interface PCB with break out leads. The connections between the contact pads on the chip and the break out leads on the PCB were bridged using a wedge wire bonder (Model 4526, Kulicke \& Soffa, Willow Grove, PA).
Finally, the chip and the wire bonds were secured using the two-part epoxy.

\section{Measurements}

5.1. Conductivity. To prepare saline test solutions, $30.169 \mathrm{~g}$ $\mathrm{NaCl}$ salt (CAS 7647-14-5, Sigma-Aldrich Co, St Louis, MO, USA) was added to a $500-\mathrm{mL}$ volumetric flask. The salt was dissolved in some deionized water at room temperature, after which additional water was added until the full volume was reached. This solution was diluted in seven subsequent steps, each producing a solution with half the concentration to that of the previous one. This resulted in eight saline solutions of decreasing concentration, denominated henceforth as Sol. 1 to Sol. 8, ranging in salinity from brine, approximately $60.34 \%$, to freshwater, approximately $0.47 \%$.

Approximately $0.05 \mathrm{~mL}$ large droplets from the different solutions were applied to cover the surface of the conductivity electrodes, starting with the lowest concentration. A sinusoidal voltage of $100 \mathrm{mV}$ (Vpp) was applied in a frequency range of $50 \mathrm{~Hz}$ to $5 \mathrm{MHz}$, in 30 logarithmic steps, over the electrodes and a shunt resistor, using a function generator (33220A, Agilent Technologies, Santa Clara, CA, USA) and an operational amplifier. The voltage drop over the shunt resistor was amplified by a second operational amplifier, and its RMS was measured using an oscilloscope (DSO7104A, Agilent Technologies, Santa Clara, CA, USA). Both instruments were controlled by a Matlab script (MathWorks Inc., Natick, MA, USA), which also recorded the measurements and calculated the absolute impedance. After each measurement scan of a solution, which took about one minute, the electrodes were thoroughly rinsed with deionized water before the next solution was applied.

To measure the repeatability of the conductivity sensor, $7.5 \mathrm{~g} \mathrm{NaCl}$ was diluted in $250 \mathrm{~mL}$ deionized water to form a $0.5 \mathrm{M}$ solution. This time, the conductivity sensor was submerged in $100 \mathrm{~mL}$ of this solution, whereupon 10 consecutive frequency-scan measurement series were performed, each taking about $1 \mathrm{~min}$.

No temperature compensation was made in these initial conductivity tests, which were all performed at room temperature.

5.2. Temperature. Temperature measurements were conducted using a temperature-controlled bath (RKP 20, MGW Lauda, Lauda-Königshofen, Germany) with an antifreeze liquid. The temperature responses were measured, using a four-point probe digital multimeter (HP 34401A, Agilent Technologies Inc, Santa Clara, CA). Because of the electrical connections used in the test setup, the chip was wrapped in a plastic foil to prevent direct contact with water and avoid cross-talk through the contact leads. As a consequence, the time response of the test setup was rather long. Before each measurement, the temperature was kept fixed for about one hour while the sensor readout was monitored, to ensure that a steady temperature had been reached in the bath.

The temperature was ramped up and down between -5 , 15 , and $40^{\circ} \mathrm{C}$, for which the sensor response was logged. Measurements for smaller temperature steps, $0.05^{\circ} \mathrm{C}$, between 


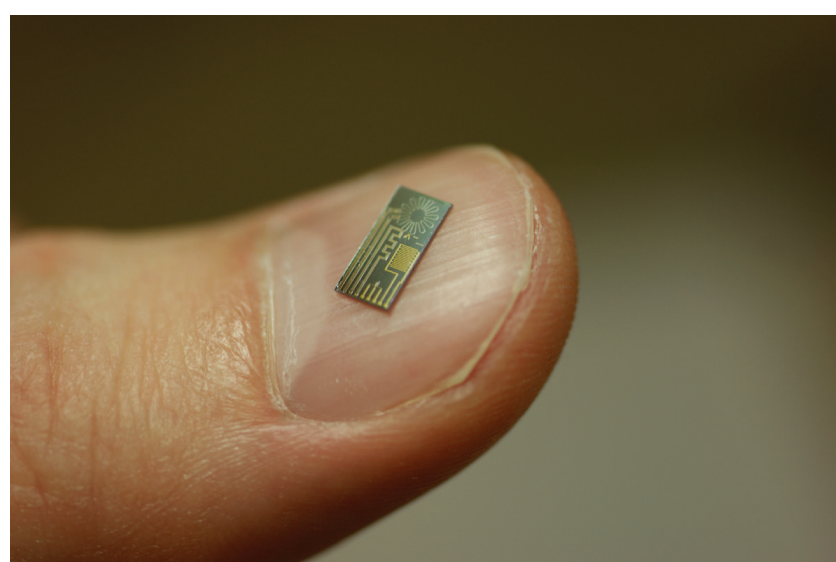

Figure 3: Manufactured chip with the conductivity, temperature, and pressure sensor elements, displayed on a thumbnail. (The overall circuit layout of the manufactured chip is somewhat different from the schematic seen in Figure 1).

$14.90^{\circ} \mathrm{C}$ and $15.10^{\circ} \mathrm{C}$, were also performed, while recording the resistance change of the sensor. Due to the smaller temperature steps, $15 \mathrm{~min}$ of stabilization was allowed before doing the measurement.

5.3. Depth. The sensor set was mounted in an airtight container equipped with two electrical feedthroughs for sensor readouts. A tube connection provided pressurized air in the range of 1 to 7 bars. The manually operated valve allowed for setting the pressure with a precision of a couple of dbars. The pressure sensor elements were characterized by switching the pressure back and forth between 1 and 2 bars, each for about $5 \mathrm{~min}$, and also by stepping through the range of 1 to 7 bars in steps of about 1 bar and $30 \mathrm{~s}$.

No temperature compensation was performed in these initial pressure tests, which were all performed at room temperature.

\section{Results}

A chip, $7.5 \times 3.5 \mathrm{~mm}$ in size, with integrated conductivity, temperature, and pressure sensors, was manufactured using thinfilm electrode deposition and etched Si membrane structures, Figure 3. Results from the individual sensors follow under their respective subheading.

6.1. Conductivity. The measured impedances for the eight different saline solutions were plotted against frequency, Figure 4 .

The results of the impedance measurements were also plotted against the concentration, to investigate the sensitivities, Figure 5, as well as against the inverse square root of the concentration, whereupon the linearity of the results was investigated, Figure 6 . The sensitivities of the lowest concentration range $(0.47$ to $0.94 \%$ ) and the highest range (15.09 to $60.34 \%$ ) were calculated and are listed in Table 3.

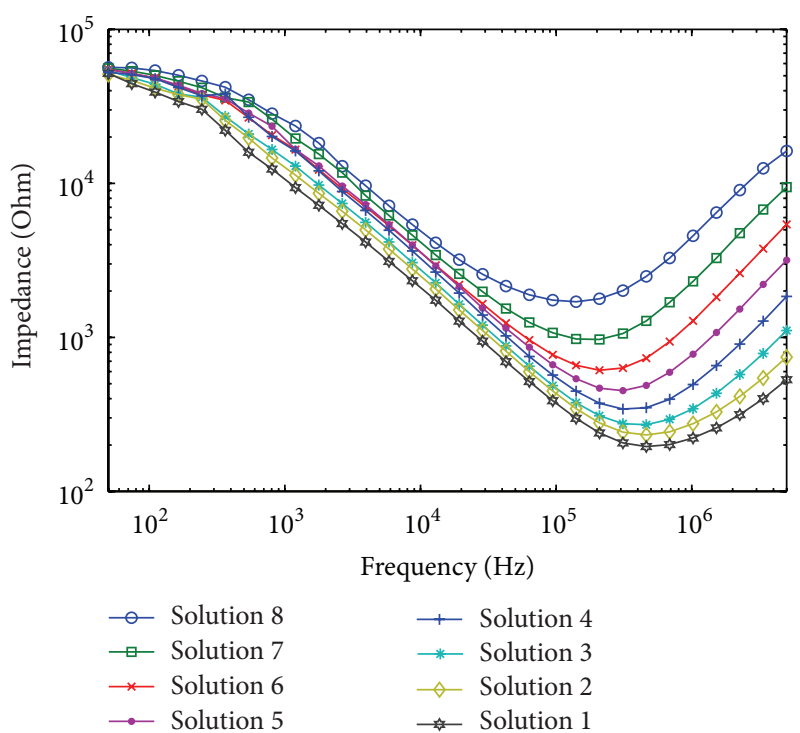

FIGURE 4: Impedance obtained for the eight solutions of $\mathrm{NaCl}$ and deionized water over a frequency range from $50 \mathrm{~Hz}$ to $5 \mathrm{MHz}$. The markers correspond to data points.

TABLE 3: Sensitivities from Figure 5 and linear fittings from Figure 6.

\begin{tabular}{lccc}
\hline Freq. $(\mathrm{Hz})$ & $\begin{array}{c}\text { Low conc. } \\
\text { Sensitivity } \\
(\Omega / \%)\end{array}$ & $\begin{array}{c}\text { High conc. } \\
\text { Sensitivity } \\
(\Omega / \%)\end{array}$ & Overall $R^{2}$ \\
\hline 19280 & 1304 & 8 & 0.8763 \\
42660 & 1313 & 4 & 0.9787 \\
461800 & 2572 & 2 & 0.9347 \\
1520000 & 6785 & 4 & 0.9442 \\
5000000 & 14409 & 13 & 0.9749 \\
\hline
\end{tabular}

TABLE 4: Average signal response and standard deviation for 10 consecutive measurements.

\begin{tabular}{lccc}
\hline Freq. (Hz) & Avg. sig. $(\Omega)$ & Std. dev. $(\Omega)$ & Std. dev. $(\%)$ \\
\hline 19280 & 344.76 & 1.1290 & 3.274 \\
42660 & 182.89 & 0.4331 & 2.368 \\
461800 & 95.33 & 0.0843 & 0.8843 \\
1520000 & 229.41 & 0.0986 & 0.4298 \\
5000000 & 706.65 & 0.7965 & 1.127 \\
\hline
\end{tabular}

Furthermore, the $R^{2}$ values of linear fittings across each graph's full length in Figure 6 are also presented in Table 3.

The 10 consecutive measurements of the salinity for a solution with salinity of $30.02 \%$ showed repeatability according to Table 4 .

6.2. Temperature. Temperature measurement results, when stepping between $-5,15$, and $40^{\circ} \mathrm{C}$, are presented in Table 5, and for 14.90 to $15.10^{\circ} \mathrm{C}$, in steps of $0.05^{\circ} \mathrm{C}$, in Table 6 .

At least to the third decimal, these measurements showed prefect repeatability and, in fact, a nonmeasurable hysteresis. Simple linear regression analysis, using the least squares 


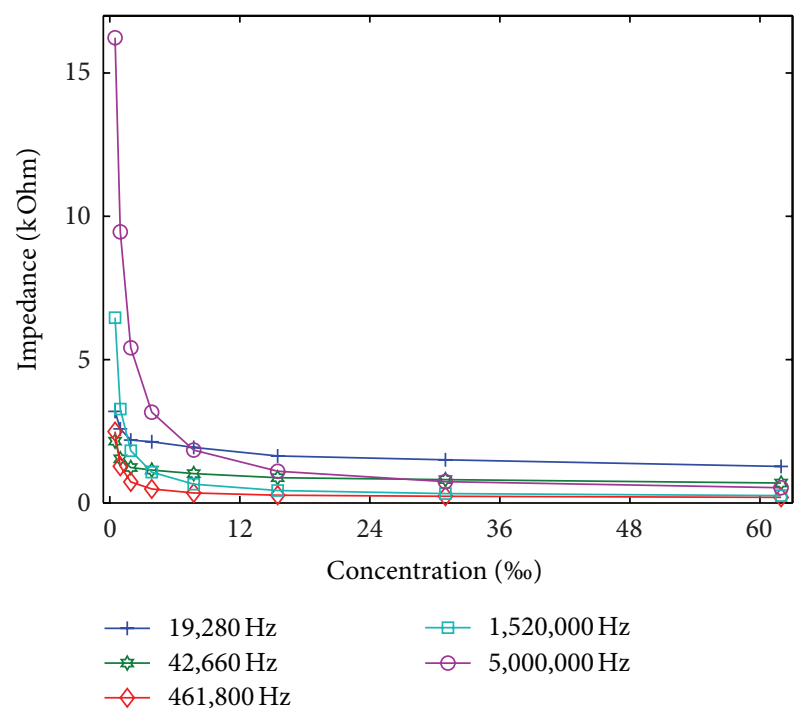

FIGURE 5: Impedance versus concentration for five selected frequencies. The markers correspond to data points.

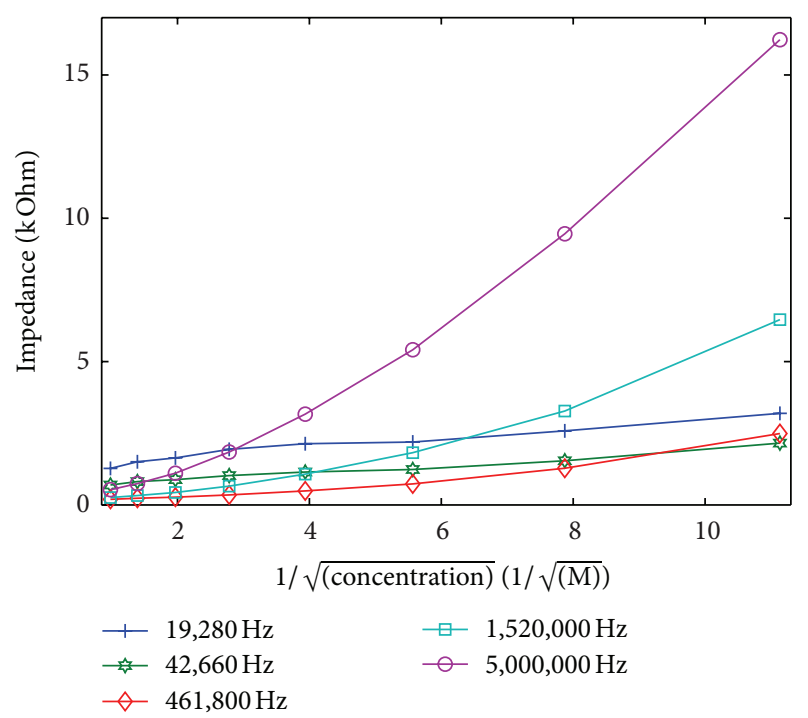

Figure 6: Impedance versus the inverse square root of the concentration for five selected frequencies. The markers correspond to data points.

method, of data in Tables 5 and 6 , in both cases resulted in a sensitivity of $0.100 \Omega /{ }^{\circ} \mathrm{C}$ with an $R^{2}$ of 1.000 .

These measurements were performed over the course of a day, but further measurements at $15.00^{\circ} \mathrm{C}$ overnight did not indicate any hysteresis either. Furthermore, measurements over the subsequent next three days showed a hysteresis of no more than $0.001 \Omega$ (corresponding to $<0.2 \mathrm{~m}^{\circ} \mathrm{C}$ ) from the previously obtained values, which, however, was within the specified resolution of the multimeter used for that time span.

6.3. Depth. The average instantaneous values of the signal output from 20 switches between 1 and 2 bars and the standard deviations are presented in Table 7. Over time, a drift of the sensor output signal was noted.
TABLE 5: Sensor response versus bath temperatures $-5,15$, and $40^{\circ} \mathrm{C}$.

\begin{tabular}{lcc}
\hline Measurement & Bath temperature $\left({ }^{\circ} \mathrm{C}\right)$ & Sensor resistance $(\Omega)$ \\
\hline 1 & 40.00 & 80.233 \\
2 & 15.00 & 77.744 \\
3 & -5.00 & 75.727 \\
4 & 15.00 & 77.744 \\
5 & 40.00 & 80.233 \\
6 & 15.00 & 77.744 \\
7 & -5.00 & 75.727 \\
8 & 15.00 & 77.744 \\
\hline
\end{tabular}

TABLE 6: Sensor response versus temperature for 14.90 to $15.10^{\circ} \mathrm{C}$, in steps of $0.05^{\circ} \mathrm{C}$.

\begin{tabular}{lcc}
\hline Measurement & Bath temperature $\left({ }^{\circ} \mathrm{C}\right)$ & Sensor resistance $(\Omega)$ \\
\hline 1 & 15.00 & 77.744 \\
2 & 14.95 & 77.739 \\
3 & 14.90 & 77.734 \\
4 & 15.05 & 77.749 \\
5 & 15.10 & 77.754 \\
6 & 15.00 & 77.744 \\
\hline
\end{tabular}

TABLE 7: Average instantaneous signal output (change in resistance) and standard deviation (signal as well as pressure equivalent) for the pressure sensors when switching 20 times between 1 and 2 bars.

\begin{tabular}{lccc}
\hline $\begin{array}{l}\text { Pressure } \\
\text { sensor }\end{array}$ & $\begin{array}{c}\text { Average } \\
\text { signal }(\Omega)\end{array}$ & $\begin{array}{c}\text { Std. dev. } \\
(\Omega)\end{array}$ & $\begin{array}{c}\text { Std. dev. } \\
(\mathrm{mbar})\end{array}$ \\
\hline P1 & 0.21 & 0.02 & 2.4 \\
P2 & 0.18 & 0.01 & 1.2 \\
P3 & 0.12 & 0.01 & 1.2 \\
P4 & 0.16 & 0.01 & 1.2 \\
\hline
\end{tabular}

The averages from four measurement series of pressure increasing from 1 bar to 7 bars, in steps of 1 bar, for sensor P4 are presented in Figure 7. The step responses decreased slightly from the earlier test when reaching higher pressures, with a step size of $0.11 \Omega$ for the last two pressure steps. The standard deviation of the different series was at most $0.01 \Omega$. A linear fit to the graph gave a sensitivity of $0.1185 \Omega /$ bar with $R^{2}=0.9964$.

\section{Discussion}

A chip with conductivity, temperature, and pressure sensor elements has been manufactured and evaluated. Although, the accuracy has not been determined, the results from conductivity and temperature measurements are promising for the intended application as a miniaturized CTD instrument for, for example, miniaturized submersibles and biologger on marine animals.

Besides integrability and small size, data transfer and power consumption are important issues in such applications. The estimated power consumption for a complete CTD instrument is about $10 \mathrm{~mW}$, which is a small entry 


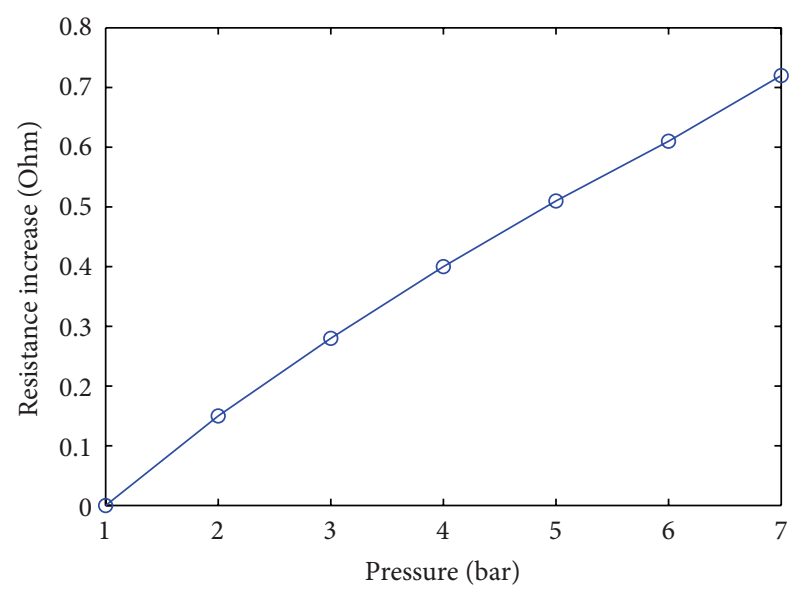

FIGURE 7: Resistance increase versus increase in pressure for sensor P4.

in the power budget of the DADU vehicle [26] totaling on a few Watts. Since the submersible is tethered with an optical fiber, data transfer rate is not limiting in this case. Unless continuous operation is required, power should not be a concern when used as an animal-borne device, either. However, if data shall not only be stored for a final retrieval, but instead transferred in bursts when the animal surfaces, a clever data compression algorithm might be necessary. It appears as if similar problems have been solved [19].

In the following, the performances of the individual sensor elements are commented on.

7.1. Conductivity. The impedance measurements at different frequencies indicate an increasing stability (in terms of curve smoothness) and resolution between the different concentrations with increasing frequency, Figure 4 , where the instrumentation and electronics set a limit at $5 \mathrm{MHz}$. For low frequencies, the impedance decreases with increasing frequency, until this dependence is reversed and the impedance starts to increase with the frequency, at $0.1 \mathrm{MHz}$ for the most diluted solution and at $0.5 \mathrm{MHz}$ for the least diluted one.

The impedance measurements exhibited a much higher sensitivity at the lower range of the measured concentrations, from freshwater into the brackish region, than at the higher range, from brackish into the brine region, Figure 5 and Table 3.

As is seen in Figure 6, the impedance versus the inverse square root of the concentration plots is generally slightly curved indicating, perhaps, that Kohlrausch's Law [42] is not straightforwardly applicable in this case. Although poorly modelled and understood, the result is well behaved enough to allow for a simple calibration procedure, which, however, is not within the scope of this work.

The highest $R^{2}$ value was obtained for a frequency of $42,660 \mathrm{~Hz}$. At lower frequencies, the $R^{2}$ value was lower due to variations in the measurements. At higher frequencies, there was a dip in the $R^{2}$ value, after which the $R^{2}$ value increased again with frequency, Table 3.
For the repeatability in the 10 consecutive measurements, the standard deviation was lowest for the frequencies of 461,800 $\mathrm{Hz}$ and 1,520,000 Hz, Table 4 .

Based on the characterization of the conductivity sensor, and with regard to sensitivity, only, operation at the higher end $(5 \mathrm{MHz})$ of the frequency range would be preferable. Here, the linear fit is also relatively good, Table 3 . However, the repeatability is lower (i.e., relative standard deviation, Table 4, is larger) than that for measurements at 1,520,000 Hz. A good compromise for the operation frequency could therefore be somewhere between these two frequencies.

7.2. Temperature. With the current design of the temperature sensor's contact leads, especially the bond wires, it was suspected that some initial variations in the measurements were caused by the two-part epoxy taking up water. Therefore, the measurements were performed in an encased dry environment in the temperature bath, which resulted in improved performance.

The temperature sensor measurements showed an excellent linear response and repeatability in the temperature range of -5 to $40^{\circ} \mathrm{C}$. The precision of the sensor was found to be at least $\pm 0.005^{\circ} \mathrm{C}$, corresponding to a resistance change of $0.001 \Omega$, Table 6 , which was the resolution of the multimeter used in the measurements.

7.3. Depth. Due to the available resources for testing of the pressure sensor, it could only be evaluated for up to 7 bars air pressure and at roughly 1-bar intervals (to an accuracy of about \pm 0.05 bar). Despite this, the pressure sensors showed a clear repetitive response when the pressure was switched repeatedly between 1 and 2 bars. For higher pressures, the step size decreased somewhat. The pressure levels for these tests, however, were only set roughly, using a needle gauge and a manually operated valve.

Although designed for a limited pressure interval, the P4 pressure sensor element showed a decreased signal output of only one-fourth when compared with that of $\mathrm{P} 1$, at a pressure change from 1 to 2 bars, suggesting that this single design, P4, could be used for the whole pressure range, from atmosphere and down to $1000 \mathrm{~m}$, and still has a potential for subbar resolutions at lesser depths.

However, the pressure sensor showed a long-term drift, the source of which has not been identified. A temperature sensitivity of roughly $1 \Omega /{ }^{\circ} \mathrm{C}$ was found for the $\mathrm{NiCr}$ meander structures, which is significant in comparison with the low signal levels at 1-bar increments of pressure (corresponding to approx. $0.1^{\circ} \mathrm{C}$ ). However, this corresponds to a TCR very close to its bulk value. The temperature effect on the pressure measurements should be decreased by using the elements for temperature compensation. Due to limitations with the pressure test setup, these were not included in these tests. Furthermore, preliminary investigations using a mechanical probe showed much more stable signal levels, suggesting that the drift seen in the pressure tests is somewhat related to this test setup. 
7.4. Salinity. Based on the measurements of conductivity, temperature, and depth, indicating uncertainties of $\pm 0.14 \%$, $\pm 0.01 \%$, and $\pm 12.5 \%$, respectively, it is clear that the present device is suited for miniaturized salinity measurements. It should, however, be pointed out that this type of measurements requires adequate calibration procedures.

7.5. Future Improvements. Future improvements of this CTD concept will be to include four-probe leads all the way to the sensor elements on the chip, in order to mitigate the lead and contacting resistance effect on the measurements. In the current version, four-probe measurements were only applicable for the temperature sensor and only to the chip contact pads, not all the way to the sensor elements.

Temperature compensation of the conductivity and pressure measurements should be included, through which higher accuracies and better long-term stabilities are expected.

The measurements would also benefit from using a waterproof encapsulation technique, as investigated by [43].

Standardized saline solutions should be acquired and used, to directly relate conductivity signals to standard solutions.

A better pressure test setup should be used, to facilitate measurements at higher pressures and with more accurate pressure level adjustments.

Future work on this CTD chip will be to include a housing and integrated electronics and to perform more in-depth reference measurements as well as field tests.

\section{Conclusions}

A chip with conductivity, temperature, and pressure sensor elements has been manufactured and evaluated. Although, the accuracy has not been determined, the conductivity and temperature measurements show promise for the intended application as a miniaturized CTD instrument for, for example, miniaturized submersibles and biologgers on marine animals, especially when small size, which for instance allows for distributed measurements, is of higher priority than data acquisition accuracy.

\section{Acknowledgments}

The authors would like to acknowledge the financial support from MISTRA, The foundation for strategic environmental research, Sweden, and the engineering support from Johan Sundqvist, Ångström Space Technology Centre, Uppsala University.

\section{References}

[1] S. Rahmstorf, "Ocean circulation and climate during the past 120,000 years," Nature, vol. 419, no. 6903, pp. 207-214, 2002.

[2] W. Stumm and J. J. Morgan, Aquatic Chemistry -An Introduction Emphasizing Chemical Equilibria in Natural Waters, Wiley Interscience, 1981.
[3] K. Caldeira and M. E. Wickett, "Anthropogenic carbon and ocean pH," Nature, vol. 425, no. 6956, p. 365, 2003.

[4] C. Sheppard, S. Davy, and G. Pilling, The Biology of Coral Reefs, Oxford Scholarship Online, 2009.

[5] O. Hoegh-Guldberg, P. J. Mumby, A. J. Hooten et al., "Coral reefs under rapid climate change and ocean acidification," Science, vol. 318, no. 5857, pp. 1737-1742, 2007.

[6] J. A. Kleypas, R. W. Buddemeier, D. Archer, J.-P. Gattuso, C. Langdon, and B. N. Opdyke, "Geochemical consequences of increased atmospheric carbon dioxide on coral reefs," Science, vol. 284, no. 5411, pp. 118-120, 1999.

[7] U. Riebesell, I. Zondervan, B. Rost, P. D. Tortell, R. E. Zeebe, and F. M. M. Morel, "Reduced calcification of marine plankton in response to increased atmospheric $\mathrm{CO}_{2}$," Nature, vol. 407, no, 6802, pp. 364-366, 2000.

[8] B. A. Seibel and P. J. Walsh, "Carbon cycle: potential impacts of $\mathrm{CO}_{2}$ injection on deep-sea biota," Science, vol. 294, no. 5541, pp. 319-320, 2001.

[9] E. L. Lewis, "The practical salinity scale 1978 and its antecedents," IEEE Journal of Oceanic Engineering, vol. OE-5, no. 1, pp. 3-8, 1980.

[10] N. P. Fofonoff and R. C. Millard, "Algorithms for computation of fundamental properties of seawater," UNESCO Technical Papers in Marine Science 44, 1983.

[11] H. Minato, Y. Kakui, A. Nishimoto, and M. Nanjo, "Remote refractive index difference meter for salinity sensor," IEEE Transactions on Instrumentation and Measurement, vol. 38, no. 2, pp. 608-612, 1989.

[12] L. S. Clescerl, A. E. Gyreenberg, and A. D. Eaton, Eds., Standard Methods for the Examination of Water and Wastewater, part 2520, American Public Health Assocation, American Water Works Association \& Water Environment Federation, 220th edition.

[13] D. M. Le Vine, G. S. E. Lagerloef, F. Pellerano, and F. R. Colomb, "The Aquarius/SAC-D mission and status of the Aquarius instrument," in Proceedings of the 10th Specialist Meeting of Microwave Radiometry and Remote Sensing of the Environment (MICRORAD '08), March 2008.

[14] Y. H. Kerr, P. Waldteufel, J.-P. Wigneron, J.-M. Martinuzzi, J. Font, and M. Berger, "Soil moisture retrieval from space: The Soil Moisture and Ocean Salinity (SMOS) mission," IEEE Transactions on Geoscience and Remote Sensing, vol. 39, no. 8, pp. 1729-1735, 2001.

[15] R. H. Stewart, Introduction to Physical Oceanography, Texas A\&M University, 2008.

[16] S. C. Riser, L. Ren, and A. Wong, "Salinity in Argo," Oceanography, vol. 21, no. 1, pp. 56-67, 2008.

[17] J. Jonsson, J. Sundqvist, H. Nguyen et al., "Miniaturized submersible for exploration of small aqueous environments," in Proceedings of the MTS/IEEE Kona Conference (OCEANS'11), September 2011.

[18] J. Jonsson, S. Ogden, L. Johansson, K. Hjort, and G. Thornell, "Acoustically enriching, large-depth aquatic sampler," Lab on a Chip, vol. 12, no. 9, pp. 1619-1628, 2012.

[19] M. Biuw, L. Boehme, C. Guinet et al., "Variations in behavior and condition of a Southern Ocean top predator in relation to in situ oceanographic conditions," Proceedings of the National Academy of Sciences of the United States of America, vol. 104, no. 34, pp. 13705-13710, 2007.

[20] S. Neuenfeldt, H.-H. Hinrichsen, A. Nielsen, and K. H. Andersen, "Reconstructing migrations of individual cod (Gadus 
morhua L.) in the Baltic Sea by using electronic data storage tags," Fisheries Oceanography, vol. 16, no. 6, pp. 526-535, 2007.

[21] A. Hyldgård, D. Mortensen, K. Birkelund, O. Hansen, and E. V. Thomsen, "Autonomous multi-sensor micro-system for measurement of ocean water salinity," Sensors and Actuators A, vol. 147, no. 2, pp. 474-484, 2008.

[22] K. Birkelund, A. Hyldgård, D. Mortensen, and E. V. Thomsen, "Miniaturized multi-sensor for aquatic studies," Measurement Science and Technology, vol. 22, no. 5, Article ID 055802, 2011.

[23] H. A. Broadbent, S. Z. Ivanov, and D. P. Fries, "A miniature, low cost CTD system for coastal salinity measurements," Measurement Science and Technology, vol. 18, no. 11, pp. 3295-3302, 2007.

[24] H. A. Broadbent, T. P. Ketterl, and C. S. Reid, "A miniature rigid/flex salinity measurement device fabricated using printed circuit processing techniques," Journal of Micromechanics and Microengineering, vol. 20, no. 8, Article ID 085008, 2010.

[25] X. Huang, R. W. Pascal, K. Chamberlain, C. J. Banks, M. Mowlem, and H. Morgan, "A miniature, high precision conductivity and temperature sensor system for ocean monitoring," IEEE Sensors Journal, vol. 11, no. 12, pp. 3246-3252, 2011.

[26] J. Jonsson, J. Sundqvist, H. Nguyen et al., "Instrumentation and vehicle platform of a miniaturized submersible for exploration of terrestrial and extraterrestrial aqueous environments," Acta Astronautica, vol. 79, pp. 203-211, 2012.

[27] M. J. Siegert, J. C. Ellis-Evans, M. Tranter et al., "Physical, chemical and biological processes in Lake Vostok and other Antarctic subglacial lakes," Nature, vol. 414, no. 6864, pp. 603609, 2001.

[28] L. M. Cowardin, Classification of Wetlands and Deepwater Habitats of the United States, Diane, Darby, Pa, USA, 1979.

[29] U. T. Hammer, Saline Lake Ecosystems of the World, chapter 2, Dr. W. Junk, Dordrecht, The Netherlands, 1986.

[30] R. S. Ayers and D. W. Westcot, Water Quality for Agriculture, Chapter 1, Food and Agriculture Organization of the United Nations, Rome, Italy, 1985.

[31] I. Steinhorn, "In situ salt precipitation at the Dead Sea," Limnology \& Oceanography, vol. 28, no. 3, pp. 580-583, 1983.

[32] W. Dittmar, Reports on Researches Into the Composition of Ocean Water, Collected by HMS Challenger, vol. 1 of Physics and Chemistry, Challenger Reports, 1884.

[33] D. E. Carritt and J. H. Carpenter, "The composition of seawater and the salinity-chlorinity-density problems," in Conference on Physical and Chemical Properties of Sea Water, pp. 67-86, National Academies, Easton, Md, USA, 19581959.

[34] UNESCO, "The International System of Units (SI) in Oceanography," Technical Papers in Marine Science, vol. 45, p. 124, 1985.

[35] R. G. Perkin and E. L. Lewis, "The Practical Salinity Scale 1978: fitting the data," IEEE Journal of Oceanic Engineering, vol. 5, no. 1, pp. 9-16, 1980.

[36] H. Preston-Thomas, "International temperature scale of 1990 (ITS-90)," Metrologia, vol. 27, no. 1, pp. 3-10, 1990.

[37] F. J. Millero, R. Feistel, D. G. Wright, and T. J. McDougall, “The composition of Standard Seawater and the definition of the Reference-Composition Salinity Scale," Deep Sea Research I, vol. 55, no. 1, pp. 50-72, 2008.

[38] W. Olthuis, W. Streekstra, and P. Bergveld, "Theoretical and experimental determination of cell constants of planarinterdigitated electrolyte conductivity sensors," Sensors and Actuators B, vol. 24, no. 1-3, pp. 252-256, 1995.

[39] T. A. Gregory, Micromachined Transducers Sourcebook, McGraw-Hill, 1998.
[40] L. Klintberg, M. Karlsson, L. Stenmark, J.-Å. Schweitz, and G. Thornell, "A large stroke, high force paraffin phase transition actuator," Sensors and Actuators A, vol. 96, no. 2-3, pp. 189-195, 2002.

[41] H. Kratz, M. Karlsson, A. Eriksson, J. Köhler, L. Stenmark, and G. Thornell, "Design and modeling of a thermally regulated communications module for nanospacecraft," Journal of Spacecraft and Rockets, vol. 43, no. 6, pp. 1377-1386, 2006.

[42] P. Atkin and J. Paula, Physical Chemistry, Oxford University Press, 2010.

[43] A. Hyldgård, K. Birkelund, J. Janting, and E. V. Thomsen, "Direct media exposure of MEMS multi-sensor systems using a potted-tube packaging concept," Sensors and Actuators A, vol. 142, no. 1, pp. 398-404, 2008. 

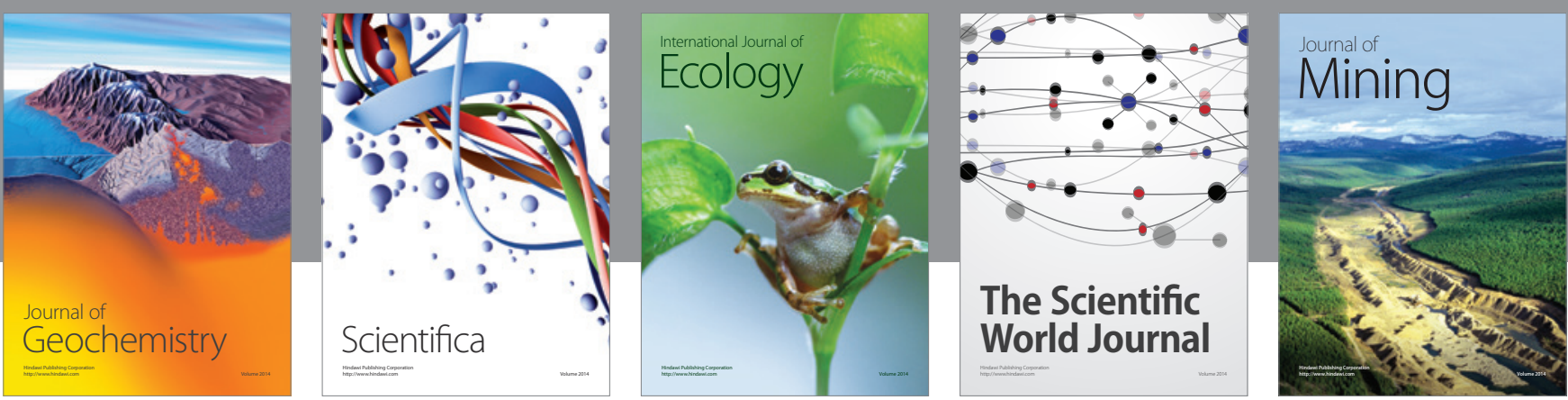

The Scientific World Journal
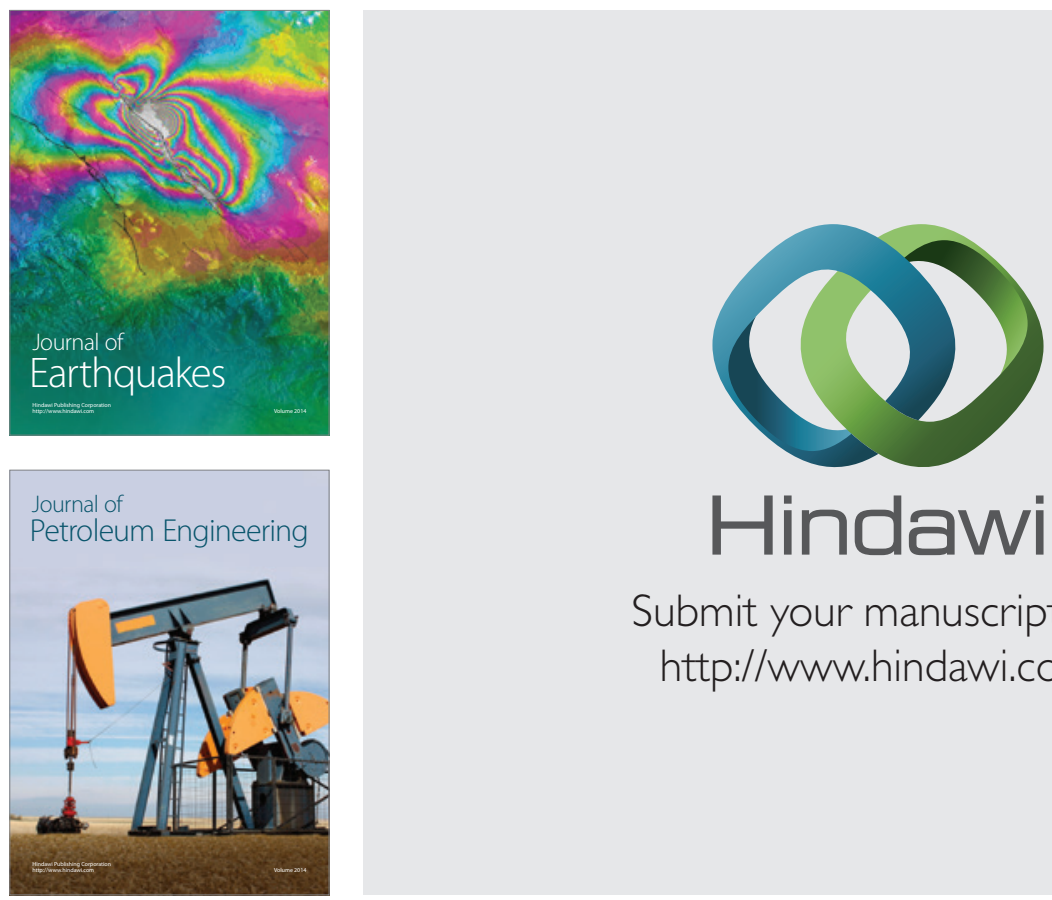

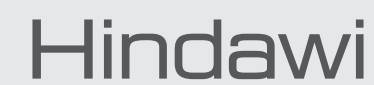

Submit your manuscripts at

http://www.hindawi.com
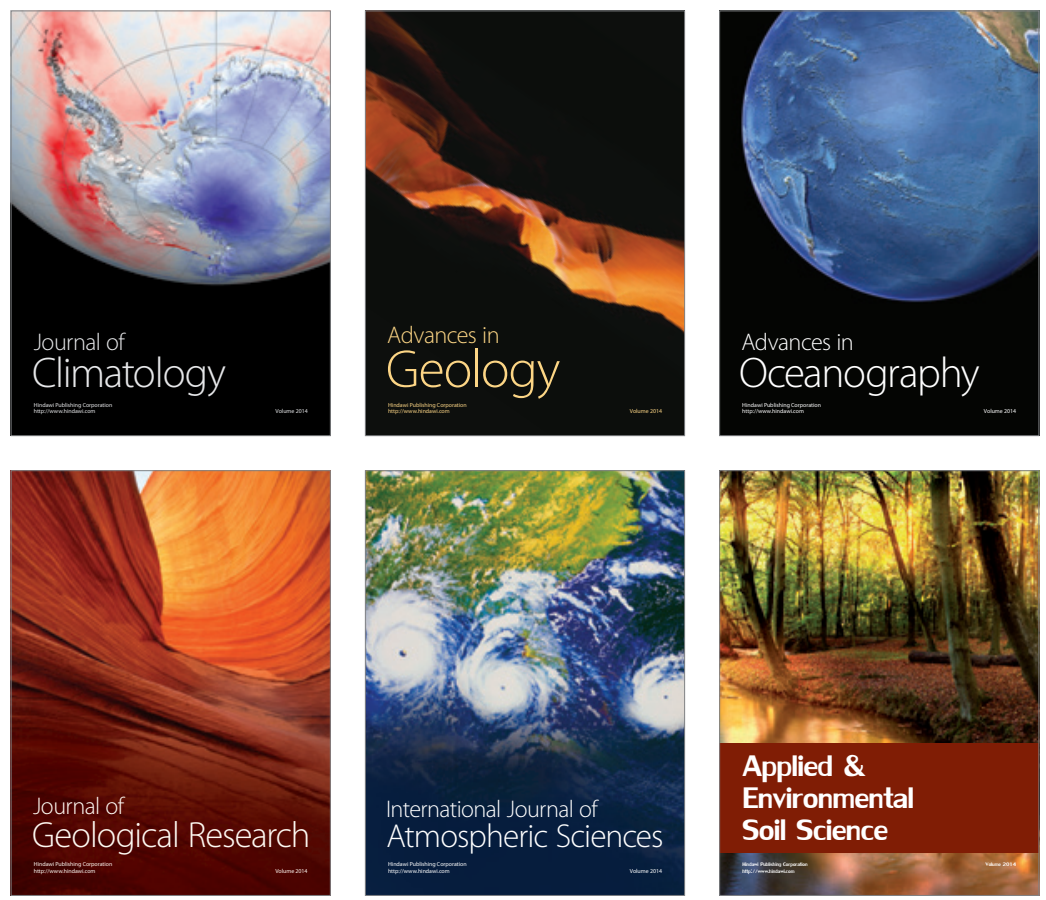
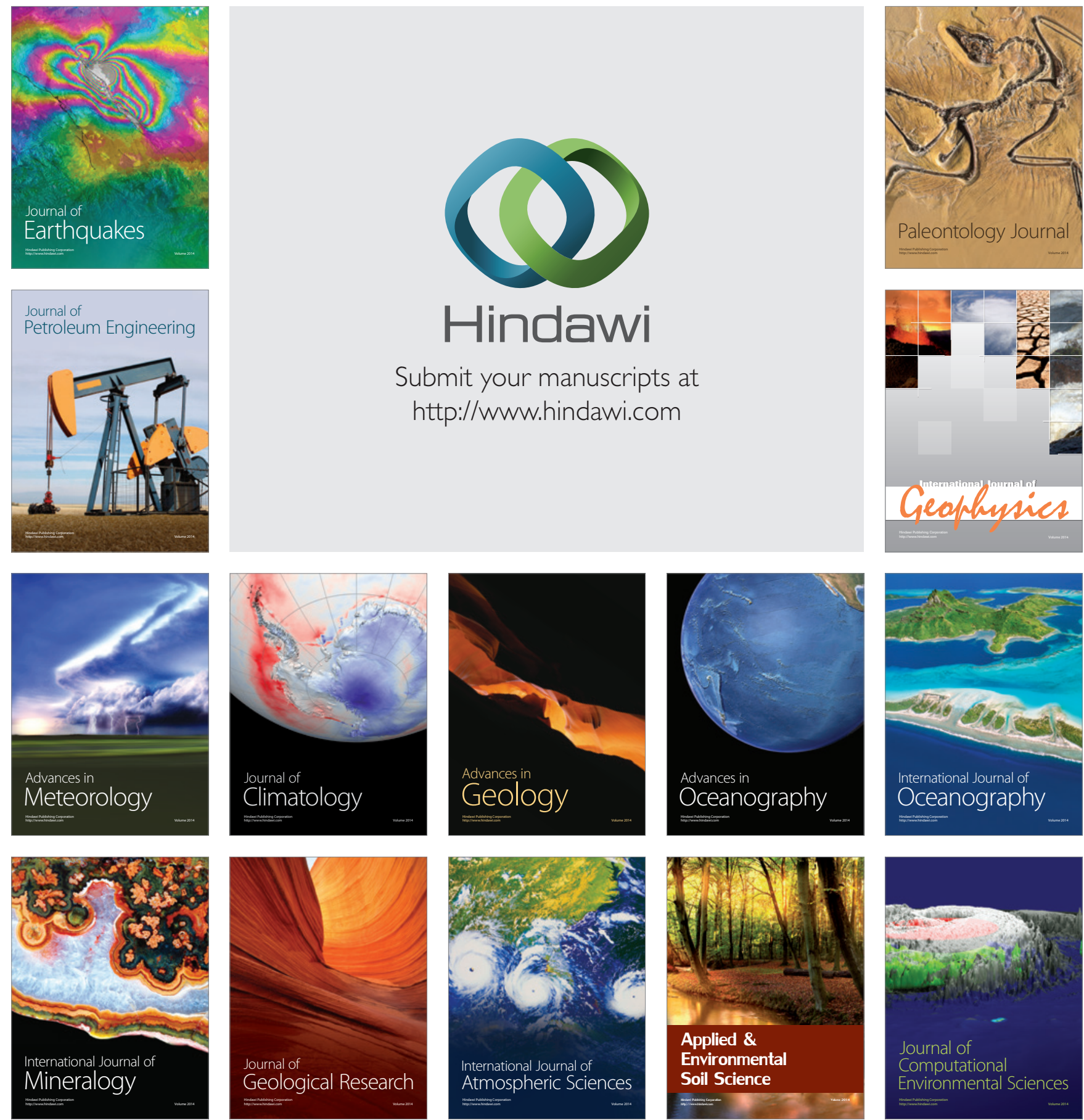